\title{
Changing Trends in Emergency Contraception
}

\author{
Roy $\mathbf{J}^{1}{ }^{1}$ Chakraborty $\mathbf{S}^{2}$ \\ ${ }^{1}$ College of Medicine and JNM Hospital, Kalyani, Nadia, West Bengal, ${ }^{2}$ Dept of Gyn/Obs, Medical College Calcutta, Kolkata
}

\begin{abstract}
Emergency contraception is defined as the use of drugs or devices to prevent pregnancy after unprotected coitus. It is sometimes referred to as 'morning after' or postcoital contraception. Global rates of unintended pregnancy are alarming and would suggest that knowledge of, and access to, emergency contraception is an area that needs to be developed ${ }^{1}$. Emergency contraception has been called the best-kept contraceptive secret. Emergency contraception provides a safe and effective means of postcoital contraception and has been estimated to prevent at least $75 \%$ of expected pregnancy resulting from unprotected intercourse Previous research shows that several regimens of postcoital contraception offer safe and effective ways for women to avoid pregnancy. Yet the methods are often unavailable to women in developing countries.
\end{abstract}

Keywords: Emergency contraception, postcoital contraception, unintended pregnancy, unprotected intercourse

\section{INTRODUCTION}

Unintended pregnancy is a global problem, which affects women, their families and society. Abortion is a frequent consequence, but in the developing world it can result in serious long-term negative effects including infertility and maternal death. The root cause of many social problems is unintended pregnancies, including teenage pregnancy, single parenthood, illiteracy amongst women and penury. Hence for the women who are interested in preventing unwanted pregnancies knowledge of emergency contraception is crucial to its utilization ${ }^{1}$. Colarossi et al have highlighted below the following points about access, barriers, awareness and acceptability with regards to emergency contraception, which may help formulate policies to propagate the use of postcoital contraception and thereby reduce the incidence of abortion and eventually maternal death ${ }^{2}$.

Also, the need for emergency contraception continues as the HIV/AIDS epidemic in most developing countries has led many women to opt for condom alone while neglecting more effective methods of contraception. Contraception failure may occur as condoms may break, split and slip off resulting in the high rate of unwanted pregnancies. (75 million per year) ${ }^{3}$. This is eventually followed by unsafe abortion as a result of the illegality of the practice in most of the developing countries. Thus, the grey areas which need to be developed in order to promulgate emergency contraception amongst women in a study done by Smith et al ${ }^{4}$ are:

\section{CORRESPONDENCE}

Somajita Chakraborty D.G.O., M.D.

Associate professor Dept of Gyn/Obs

Medical College Calcutta, Kolkata, West Bengal

83/1/1 Ballygange Place, Kolkata West Bengal

Email:mimodoc@yahoo.com 
1. Publicizing the existence of EC - The existence of the postcoital pill was known by $94.1 \%$ of women. Knowledge was greater among women in younger age groups and among women who regularly used contraception

2. Encouraging the 'source' to help create awareness amongst its users -The source of emergency contraception was identified as the general practitioner or family planning clinic.

3. Propagating the information about the correct timing of effectiveness of postcoital pill (upto 72 hours after unprotected intercourse) is of utmost importance in perspective of developing countries. This information was known to $42.9 \%$ of women in UK and significantly higher among younger women.

The ECP availability is important for adolescents in particular, because of their pattern of sexual activity and unprotected sexual encounters in the early years than among adults 5 . Previous research has documented positive associations between ECP awareness and level of parental education as well as teenagers' school performance or scholastic curriculum ${ }^{6-9}$. In a Swiss study by Ottesen et al ${ }^{8}$ ECP use was higher in girls with more than three partners, first 'love affair' before 14 years, regular sexual intercourse, unplanned first intercourse and a history of pregnancy.

\section{The changing trend}

Although emergency contraception was first used in the 1960s, it is still a largely unknown method. Traditional methods for postcoital contraception are widely practiced in some parts of the world, although with no proven efficacy, such as the use of herbs and plants, injections, urination after intercourse or an overdose of vitamin C, aspirin and chloroquine. Even tequila, Coca- Cola, marijuana with alcohol, vinegar or baking soda vaginal douches and sucking on lemons are still being tried in parts of the world ${ }^{1}$. As experimentation continued and science progressed, high dose oestrogen was first tried as a means of postcoital contraception in 1960s and early 1970s, followed by a combination of oestrogen and progestin. This regimen was superseded by the progestogen-only method. The latter has now been combined into one dose ${ }^{10}$. Also, postcoital insertion of an intrauterine device made headway as the "lingering misperceptions" of the safety of intrauterine devices disappeared with changing concepts. Mifepristone is now successfully being used for emergency contraception after its successive trials since early 1990s. In recent times, a unique molecule in a single pill, Ulipristal acetate, has shown promising results in the ongoing trials for emergency contraception.

\section{Table 1 Facts about emergency contraception}

\begin{tabular}{ll}
\hline Access & $\begin{array}{l}\text { Heard about EC primarily from friends and family. } \\
\text { Buying EC at a pharmacy is acceptable and preferable } \\
\text { to getting it from a doctor. }\end{array}$ \\
\hline Barriers & $\begin{array}{l}\text { Cost and lack of health insurance for prescription } \\
\text { coverage. } \\
\text { Distrust of doctors and pharmaceuticals. }\end{array}$ \\
Awareness & $\begin{array}{l}\text { Did not know how emergency contraception worked } \\
\text { or how to use it. Fears about safety and side effects. }\end{array}$ \\
& $\begin{array}{l}\text { Concerns that it was the same as the (medical) } \\
\text { abortion pill. }\end{array}$ \\
& $\begin{array}{l}\text { Not having enough information about contraception } \\
\text { overall from their families while growing up. }\end{array}$ \\
& $\begin{array}{l}\text { Numerous myths about how to prevent pregnancy. } \\
\text { Having fewer children is a way to achieve more and } \\
\text { take better care of the children you already have. }\end{array}$ \\
Acceptable way to prevent pregnancy, if not an \\
abortifacient. \\
Using emergency contraception may be irresponsible \\
due to having sex without a condom or other birth \\
control.
\end{tabular}

\section{Ideal emergency contraception should be:}

1. Highly effective and free of side effects

2. Should not disturb the menstrual cycle

3. Effective despite a long interval between the episode of unprotected intercourse and administration

4. Should preferably be a single dose, easily administered and affordable ${ }^{11}$

However, no available emergency contraceptive has all of these attributes; thus, the search for an ideal emergency contraceptive is still on.

\section{Who will use emergency contraception?}

1. Women having difficulties using their regular methods of contraception, such as breakage of condom, non-compliance with taking daily pills, displacement of diaphragm or cervical cap ${ }^{1}$. It is also useful for women using the withdrawal method in instances where withdrawal occurred too late and for women practicing the rhythm or calendar method with any miscalculation of the 'safe' days for periodic abstinence.

2. Women who have engaged in an unexpected sexual activity either by being forced (as in cases of rape) or coerced into having unplanned, unprotected intercourse $\mathrm{e}^{1}$

3. Non-user of contraception as a result of either fear of, or discomfort with, side effects, or lack of knowledge of availability

4. It is particularly suitable for adolescents because of their patterns of sexual behavior and contraceptive use 


\section{METHODS}

\section{Oestrogen alone}

This was the standard method used in 1960s and early 1970 s and is also called the 'five by five' regimen, as it consists of five tablets of $1 \mathrm{mg}$ ethinyl estradiol that needs to be given daily for five days. ${ }^{12-14}$ It is said to be as effective as the Yuzpe method (mentioned below) but produces more side effects. More women experience the side-effects of nausea and vomiting when using oestrogen-only regimen when compared to Yuzpe regimen. Also, there is a theoretical higher risk of thromboembolism. ${ }^{14}$ Now this regimen is of theoretical relevance only.

\section{Combined oestrogen and progestin}

Yuzpe and Lancee first described it in the late 1990s' this combination therapy is often referred to as the Yuzpe regimen. The oestrogen - progestin regimen consists of two doses of a combination of $100 \mu \mathrm{g}$ of ethinyl estradiol and $0.5 \mathrm{mg}$ of levonorgestrel each, the first dose taken within 72 hours of intercourse and the second dose 12 hours later. ${ }^{15}$ Commercially available brands of combined oral contraceptive pills can also be used. With lower dose pills a greater number of pills or double the dose of usual pill needs to be taken. The common side effects associated with this regimen are nausea and vomiting. If vomiting occurs in less than 2 hours after taking the medication, then the first dose needs to be repeated. Headaches, breast tenderness, abdominal pain and dizziness are also common complaints faced with this regimen. The subsequent period is usually on time but can be a little earlier or later, and may be rather heavy. Oestrogen -progestin regimen is absolute contraindicated in diagnosed pregnancy. No evidence is present linking its use to the risk of congenital malformations in the fetus. ${ }^{13,16}$ Hence pregnancy termination is not mandatory on this ground if this method of emergency contraception fails and perchance the woman changes her mind towards continuing her pregnancy.

\section{Progestin alone}

A recent randomised controlled trial by the WHO has shown that the levonorgestrel regimen is better tolerated and more effective than the Yuzpe regimen ${ }^{17}$. This regimen has outmoded the Yuzpe regimen. The levonorgestrel regimen consists of two doses of $0.75 \mathrm{mg}$ of levonorgestrel taken 12 hours apart starting within 48 hours of unprotected intercourse. ${ }^{18}$ Progestagens alone have been studied by WHO, but failure rates were as high as $10.1 \%$ in women with frequent intercourse. ${ }^{17}$ Regular use was therefore not recommended since cycles became unpredictable.

\section{The intrauterine contraceptive device}

The copper-bearing intrauterine device, and not LNG intrauterine device, is a highly effective postcoital contraceptive with failure rates of less than $1 \% .{ }^{19}$ It is used for up to five to seven days after unprotected intercourse and is particularly appropriate for women who wish to use the device as a long term method of contraception. However, trained health care provider and insertion under aseptic conditions are the pre-requisites. The disadvantages with this method are that it is contraindicated for women at risk of sexually transmitted diseases who are frequently the same women who need emergency contraception and also it may be difficult to insert in nulliparous women. These problems can be nullified by proper screening of women for infection, or by giving prophylactic antibiotic before insertion of the device. ${ }^{20}$

\section{Danazol}

Danazol is an anti-gonadotrophin, synthetic progestin with androgenic properties. The danazol regimen consists of $400 \mathrm{mg}$ each taken 12 hours apart with the first dose given within 72 hours after unprotected intercourse. ${ }^{14}$ Other variants of this regimen also exist. Investigations on the danazol regimen for emergency contraception have shown that the two largest trials have conflicting results. A trial by Zuliani et al concluded that the method is effective while the randomised study by Webb et al suggested that danazol may be ineffective as a postcoital pill. ${ }^{21}$ The advantages of this regimen are that the incidence of its side effects are less severe than those associated with the Yuzpe method and also that it can be taken by women with contraindications to combined oral contraceptives or oestrogen. This regimen is now of theoretical relevance because of the controversy as regards to its effectiveness, and disadvantages such as expensiveness and less ready availability of the medicine.

\section{Anti-progestins}

\section{A Mifepristone}

Mifepristone is a synthetic steroid with potent antiprogestational and anti-glucocorticoid properties that provides an effective medical method of inducing abortion in early pregnancy. The drug is highly effective as an emergency contraceptive and inhibits implantation as well as ovulation. The regimen for emergency contraception consists of a single dose of $600 \mathrm{mg}$ of mifepristone given within 72 hours of unprotected intercourse. All the side effects noticed with the other methods were much less common among the women given mifepristone, except for the delay in the onset of next menses. Mifepristone is better tolerated than the Yuzpe regimen. A study by Ashok et al, in 2001, found a decreased efficacy with the Yuzpe regimen with increasing time from coitus to treatment, with no significant relationship between efficacy and 
timing of treatment with mifepristone although the failure rates were very small. Published results from their study have shown mifepristone to be effective up to 120 hours after unprotected intercourse in a $200 \mathrm{mg}$ dose..$^{22}$ Mifepristone is promising as an emergency contraceptive and has good patient acceptability and compliance with minimal side effects compared with currently available methods of emergency contraception.

The WHO, in its multicentre randomised trial has assessed the safety and effectiveness of lower doses of mifepristone (50 and $10 \mathrm{mg}$ ) and a longer postcoital treatment period ( 120 hours) as an emergency contraceptive. This regimen is cheaper and less likely to delay the onset of the next menstrual period. It would have been 'ideal' to use a very low dose of mifepristone $(10 \mathrm{mg}$ ) as recommended by but due to the unavailability of mifepristone in a smaller dose in the UK we used a 100 $\mathrm{mg}$ dose. The disadvantage with the lower dose is that menstrual delay caused anxiety and exposes the woman to the risk of pregnancy should she have further acts of coitus. Mifepristone has effectiveness equivalent to 1500 micrograms of LNG when used as hormonal emergency contraception.

\section{B Ulipristal acetate}

Ulipristal acetate is a progesterone receptor modulator. This molecule is the most recent introduction to the gallery of postcoital contraception, and is still in the trial phase. As an emergency contraceptive, a $30-\mathrm{mg}$ micronized formulation is effective for use up to $120 \mathrm{~h}$ from unprotected sexual intercourse. ${ }^{23}$ Ulipristal acetate acts as an antagonist of the progesterone receptor at the transcriptional level and a competitive antagonist of glucocorticoid receptor function. Ulipristal, not known to have abortifacient properties has been shown to have similar efficacy to LNG in an RCT. ${ }^{24}$

The adverse effects were mainly mild or moderate, the most frequent being headache, nausea, and abdominal pain. Cycle length increased a mean of 2.8 days, whereas the duration of menstrual bleeding did not change. ${ }^{25}$ It may have several advantages over currently approved emergency contraceptives. When compared to levonorgestrel, ulipristal acetate maintains its efficacy for a full $120 \mathrm{~h}$, whereas levonorgestrel formulations have declining efficacy over that time frame. Moreover, although the copper intrauterine device (IUD) is highly effective as an emergency contraceptive, accessibility is an issue since the IUD requires a skilled provider for insertion.

\section{Cox 2 inhibitor}

It has been shown that meloxicam, a cox-2 inhibitor, can prevent rupture of the dominant follicle even after the ovulatory process has been triggered by the luteinizing hormone surge, and so, its addition to LNG might improve the efficacy of LNG emergency contraception. ${ }^{26}$ A similar delay in follicular rupture has been found using rofecoxib. ${ }^{27}$ Studies are underway to determine the authenticity of combined prescription of cox-2 inhibitor with LNG for emergency contraception.

How does emergency contraception work? In a recent review of literature by Croxatto et $\mathrm{al}^{28}$ on the mechanism of action of hormonal preparations used for emergency contraception, it is evident that further research to fully determine the mode of action is needed to bridge the gap of information that hinders a clear-cut answer to the mechanism by which emergency contraception prevents pregnancy. Although the exact mechanisms of action have not been identified, it is clear that the method prevents pregnancy from starting. This is evident by the fact that emergency contraceptive pills do not cause abortions and are ineffective if a woman is already pregnant. All emergency contraceptives currently in use act before implantation. ${ }^{14}$ Recent studies done on the mechanisms of action show that emergency contraceptive pills may prevent or delay ovulation. They may also disrupt the luteal phase of the cycle, thus interfering with fertilisation, or may interfere with implantation by altering the lining of the womb so that a fertilised egg is less likely to implant. They may also alter the activity of the fallopian tube so that the egg and sperm are less likely to meet ${ }^{13}$. There is a lack of evidence regarding the efficacy of emergency contraception, partially - and obviously because of ethical issues.

\section{CONCLUSION}

Emergency contraceptive pills are gradually becoming a more widely known, accepted and used contraceptive method in various countries. Hence, planning and allocation of resources in this field are necessary. However, postcoital contraception should never be a replacement of regular contraceptive practice. It should be the prerogative of the medical body and administration to enforce such a law that it does not become an uncontrolled over the counter medication. We at the clinical strata get to see those patients having complications after EC. Majority of them are lost to follow up. So, the long term side-effects cannot be determined. Formerly, medical termination of pregnancy had been the popular method of family planning. Now, the situation should not be such that EC replaces MTP as a future birth control method. Thus, it should be enforced that there is proper one-to-one counseling between doctors and patients so that information about EC and its complications can be communicated. Also, emergency pill should be made available only after producing a valid prescription to the pharmacists and not otherwise. Reasonable guidance, friendly law and a sympathetic counseling would be a key to the success for popularizing 
EC at its best and would eventually be beneficial in reducing maternal mortality and morbidity caused by unsafe abortion practices for unintended pregnancies in developing countries like ours.

\section{REFERENCE}

1. Haggai DNP. Emergency contraception: the journey so far. $\mathrm{Br} \mathrm{J}$ Obstet Gynaecol. 2003;110(4):339-45.

2. Colarossi L, Billowitz M, Breitbart V. Developing Culturally Relevant Educational Materials About Emergency Contraception. Journal of Health Communication. 2010;15(5):502-15.

3. Managing complications in pregnancy and childbirth (MCPC) WHO,UNICEF,UNFPA, WORLD BANKguideline to trainers presentation AMDD development of reproductive health and research,WHO2000.

4. Smith BH, Gurney EM, Aboulela L, Templeton A .Emergency contraception: a survey of women's knowledge and attitudes. BJOG. 1996;103(11):1109-16.

5. Anderson JE, Santelli JS, Morrow B. Trends in adolescent contracep- tive use, unprotected and poorly protected sex, 19912003. J Ado- lesc Health. 2006;38(6):734-9.

6. Aiken AM, Gold MA, Parker AM. Changes in young women's awareness, attitudes, and perceived barriers to using emergency contraception. J Pediatr Adolesc Gynecol. 2005;18(1):25-32.

7. Falah-Hassani K, Kosunen E, Shiri R, Rimpela A. Emergency contraception among Finnish adolescents: awareness, use and the effect of non-prescription status. BMC Public Health. 2007;7:201.

8. Ottesen S, Narring F, Renteria SC, Michaud PA. Emergency contracep- tion among teenagers in Switzerland: a cross-sectional survey on the sexuality of 16 - to 20 -year-olds. J Adolesc Health. 2002;31(1):101-10

9. Lete I, Cabero L, Alvarez D, Olle C. Observational study on the use of emergency contraception in Spain: results of a national survey. Eur J Contracept Reprod Health Care. 2003;8(4):203-9.

10. Rowlands S. New technologies in contraception. BJOG. 2009;116(2):230-9.

11. von Hertzen $H$, Van Look PFA. Research on new methods of contraception. Fam Plann Perspect. 1996;22(2):62-8.

12. Ellertson C. History and efficacy of emergency contraception: beyond Coca-Cola. Fam Plann Perspect. 1996;22(2):52-6

13. Glasier A. Emergency postcoital contraception. N Engl J Med. 1997;337(15):1058-64.

14. Westley E. Emergency contraception: a global overview. J Am Med Women's Assoc. 1998:53(5):215-8.
15. Yuzpe AA, Lancee WJ. Ethinylestradiol and dl-norgestrel as a postcoital contraceptive. Fertil Steril. 1997;28:932-6.

16. International Medical Advisory Panel, International Planned Parent- hood Federation. Statement on emergency contraception. Int Plan Parent Fed Med Bull. 1994;26(6):1-2.

17. Glasier A, Baird DT. Post-ovulatory contraception. Baillieres Clin Obstet Gynaecol. 1990;4(2):283-91.

18. Ho PC, Kwan MSW. A prospective randomized comparison of levonorgestrel with the Yuzpe regimen in postcoital contraception. Hum Reprod. 1993;8(3):389-92.

19. Fasoli M, Parazzini F, Cecchetti G, La Vecchia C. Postcoital contraception: an overview of published studies. Contraception. 1989;39(4):459-68

20. IUD's - an update. Popul Rep B Intrauter devices. 1995;22(5):3-10.

21. Zuliani G, Colombo UF, Molla R. Hormonal postcoital contraception with an ethinylestradiol - norgestrel combination and two danazol regimens. Eur J Obstet Gynecol Reprod Biol. 1990;37(3):253-60.

22. Ashok PW, Wagaarachchi PT, Flett GM, Templeton A. Mifepristone as a late post-coital contraceptive. Hum Reprod. 2001;16(1):72-5.

23. Russo JA, Creinin MD. Ulipristal acetate for emergency contraception. Drugs Today (Barc). 2010;46(9):655-60.

24. Creinin MD, Schlaff W, Archer DF, Wan L, Frezieres R, Thomas M, et al. Progesterone receptor modulator for emergency contraception: a randomized controlled trial. Obstet Gynecol. 2006;108(5):108997.

25. Fine $\mathrm{P}$, Mathé $\mathrm{H}$, Ginde $\mathrm{S}$, Cullins V, Morfesis J, Gainer E. Ulipristal acetate taken 48-120 hours after intercourse for emergency contraception. Obstet Gynecol. 2010;115(2):257-63.

26. Massai MR, Forcelledo ML, Brache V, Tejada AS, Salvatierra $\mathrm{AM}$, Reyes MV, et al. Does meloxicam increase the incidence of anovulation induced by single administration of levonorgestrel in emergency con- traception? A pilot study. Hum Reprod. 2007;22(2):434-9.

27. Pall $\mathrm{M}$, Friden $\mathrm{BE}$, Brannstrom $\mathrm{M}$. Induction of delayed follicular rupture in the human by the selective COX-2 inhibitor rofecoxib: a randomized double-blind study. Hum Reprod. 2001;16(7):1323-8.

28. Croxatto HB, Devoto L, Durand M, et al. Mechanism of action of hormonal preparations used for emergency contraception: a review of the literature. Contraception. 2001;63:111-21. 